\title{
Disability and treatment of specific mental and physical disorders across the world
}

Johan Ormel, Maria Petukhova, Somnath Chatterji, Sergio Aguilar-Gaxiola, Jordi Alonso, Matthias C. Angermeyer, Evelyn J. Bromet, Huibert Burger, Koen Demyttenaere, Giovanni de Girolamo, Josep Maria Haro, Irving Hwang, Elie Karam, Norito Kawakami, Jean Pierre Lépine, María Elena Medina-Mora, José Posada-Villa, Nancy Sampson, Kate Scott, T. Bedirhan Üstün, Michael Von Korff, David R.Williams, Mingyuan Zhang and Ronald C. Kessler

\section{Background}

Advocates of expanded mental health treatment assert that mental disorders are as disabling as physical disorders, but little evidence supports this assertion.

\begin{abstract}
Aims
To establish the disability and treatment of specific mental and physical disorders in high-income and low- and middleincome countries.
\end{abstract}

\section{Method}

Community epidemiological surveys were administered in 15 countries through the World Health Organization World Mental Health (WMH) Survey Initiative.

\section{Results}

Respondents in both high-income and low- and middle-income countries attributed higher disability to mental disorders than to the commonly occurring physical disorders included in the surveys. This pattern held for all disorders and also for treated disorders. Disaggregation showed that the higher disability of mental than physical disorders was limited to disability in social and personal role functioning, whereas disability in productive role functioning was generally comparable for mental and physical disorders.

\section{Conclusions}

Despite often higher disability, mental disorders are undertreated compared with physical disorders in both highincome and in low- and middle-income countries.

\section{Declaration of interest}

None. Funding detailed in Acknowledgements.
As healthcare spending continues to rise, ${ }^{1}$ resource allocation decisions will need to be based increasingly on information about prevalence, severity and chronicity of disorders and cost-effectiveness of interventions. This will require concern about specific disorders to be based not only on information about prevalence and mortality, but also on disability. ${ }^{2,3}$ Despite the fact that many studies in high-income countries have estimated the effects of specific disorders on disability, ${ }^{4-6}$ comparable broadbased studies are rare in low- and middle-income countries. ${ }^{7}$ The aims of the current report are to determine whether in both low- and middle-income and in high-income countries commonly occurring mental disorders are as seriously disabling as commonly occurring physical disorders according to respondent self-reports obtained in the World Health Organization (WHO) World Mental Health (WMH) Surveys. ${ }^{7,8}$

\section{Methods}

\section{Sample}

World Mental Health surveys were carried out in six countries classified by the World Bank as low- and middle-income (Colombia, Lebanon, Mexico, Peoples' Republic of China, South Africa, Ukraine) and nine as high-income (Belgium, France, Germany, Italy, Japan, The Netherlands, New Zealand, Spain and the USA) (see online Table DS1). The total sample size was 73 441, with individual country samples ranging from 2372 (The Netherlands) to 12992 (New Zealand). The weighted average response rate was $70.3 \%$, with country-specific response rates ranging from $45.9 \%$ (France) to $87.7 \%$ (Colombia). All surveys were based on probability household samples representative of regions (in China, Colombia, Japan, and Mexico) or nationally representative (other countries).
All interviews were conducted face to face by trained lay interviewers. Each interview had two parts. All respondents completed Part I, which contained assessments of core mental disorders. All Part I respondents who met criteria for any core mental disorder plus a probability subsample of approximately $25 \%$ of other Part I respondents were administered Part II. The latter assessed correlates, service use and disorders of secondary interest. Physical disorders were assessed in Part II. The Part II data were weighted to adjust for oversampling of people with mental disorders and for differential probabilities of selection within households and to match samples to population socio-demographic distributions.

Standardised interviewer-training procedures, WHO translation protocols and quality control procedures were applied across all WMH countries to ensure comparability. These procedures are described in more detail elsewhere. ${ }^{8}$ Informed consent was obtained in all countries. Procedures for obtaining informed consent and protecting individuals were approved and monitored for compliance by the Institutional Review Boards of the organisations coordinating the surveys in each country.

\section{Measures}

Physical disorders were assessed with a standard chronic disorders checklist ${ }^{9}$ containing ten conditions that include asthma, cancer, cardiovascular disease (hypertension, other heart disease), diabetes, musculoskeletal disorders (arthritis, chronic back/neck pain), chronic headaches, other chronic pain disorders and stomach ulcers. Respondents were asked to report whether they had had any of the symptom-based conditions (e.g. chronic headaches) in the past 12 months and to say whether a doctor had ever told them they had any of the silent conditions (e.g. hypertension) and, if so, whether they had experienced them in the past 12 months. 
Checklists of this sort yield more complete and accurate reports about chronic conditions than do open-ended questions. ${ }^{10}$ Methodological studies have documented moderate to good concordance between checklist reports and medical records in high-income countries. ${ }^{1-14}$ Comparable studies do not exist in low- and middle-income countries. Self-reports are obviously less accurate than assessments based on biological tests. Caution is consequently needed in interpreting the results of studies such as this one, that use self-report to assess physical conditions. The implications of this imperfect assessment were evaluated by replicating analyses only for people being treated for physical disorders. People being treated are more likely to meet full diagnostic criteria and to be more severely disabled than people who complete a self-report and who are not being treated. A remaining bias is that the conditions included in the checklist did not include the infectious diseases that are known to be so burdensome in low- and middle-income countries.

Mental disorders were assessed with version 3.0 of the WHO Composite International Diagnostic Interview (CIDI), ${ }^{8}$ a fully structured lay-administered interview that generates research diagnoses of commonly occurring DSM-IV mental disorders. ${ }^{15}$ The ten disorders considered here include anxiety disorders (panic disorder, generalised anxiety disorder, specific phobia, social phobia, post-traumatic stress disorder), mood disorders (major depressive disorder or dysthymia, bipolar disorder) and impulse-control disorders (intermittent explosive disorder, adult attention-deficit hyperactivity disorder, oppositional defiant disorder). Only disorders present in the past 12 months are considered. Generally good concordance has been found between CIDI diagnoses of anxiety/mood disorders and masked clinical assessment. $^{16}$ Composite International Diagnostic Interview diagnoses of impulse-control disorders have not been validated.

Treatment for physical disorders was assessed by asking respondents whether they had seen a medical doctor or other health professional in the past 12 months for the disorder. For mental disorders, disorder-specific treatment was assessed by asking each respondent whether 'you ever in your life talk(ed) to a medical doctor or other professional about (the disorder)' and, if so, whether 'you receive(d) professional treatment for (the disorder) at any time in the past 12 months'. Treatment of mental disorders was also assessed in a series of more general questions that asked respondents whether they had visited any type of professional in the past 12 months (types of professionals available varied across countries) 'for problems with your emotions, nerves, or your use of alcohol or drugs'. Self-reports about treatment have been shown in previous methodological studies to have generally good concordance with archival healthcare utilisation records, ${ }^{17}$ although this research has been carried out exclusively in high-income countries.

Disability was assessed with the Sheehan Disability Scales (SDS), a widely used self-report measure of condition-specific disability that, although up until now used only in the assessment of mental disorders, can just as well be used to assess disability caused by physical disorders. The SDS consists of four questions, each asking the respondent to rate on a $0-10$ scale the extent to which a particular disorder 'interfered with' activities in one of four role domains during the month in the past year when the disorder was most severe. The four domains are:

(a) 'your home management, like cleaning, shopping, and taking care of the (house/apartment)' (home);

(b) 'your ability to work' (work);

(c) 'your social life' (social); (d) 'your ability to form and maintain close relationships with other people' (close relationships).

The 0-10 response options were presented in a visual analogue format with labels for the response options of 'None' (0), 'Mild' (1-3), 'Moderate' (4-6), 'Severe' (7-9) and 'Very severe' (10). A global SDS disability score was also created by assigning each respondent the highest SDS domain score reported across the four domains.

Previous methodological studies have documented good internal consistency reliability across the SDS domains, ${ }^{18,19}$ a result that we replicated in the WMH data by finding Cronbach's alpha (a measure of internal consistency reliability) in the range 0.820.92 across countries. Importantly, reliability was high both in high-income countries (median 0.86; interquartile range 0.840.88 ) and low- and middle-income countries (median 0.90; interquartile range $0.88-0.90$ ). Previous methodological studies also have documented good discrimination between role functioning of cases and controls based on SDS scores in studies of social phobia, ${ }^{18}$ panic disorder, ${ }^{19}$ post-traumatic stress disorder ${ }^{20}$ and

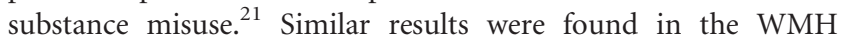
surveys based on responses to a question asked after the SDS about days out of role: 'How many days out of 365 in the past year were you totally unable to work or carry out your normal activities because of (the illness)?' We examined the strength of SDS scores predicting variation in this relatively objective measure of disability. If the SDS measures genuine disability, we would expect correlations to be significant and comparable for physical and mental disorders. This is, in fact, what we found. In high-income countries, the multiple correlations of the four SDS domain scores predicting days out of role were 0.55 for mental disorders and 0.50 for physical disorders. The comparable correlations in low- and middle-income countries were 0.39 for mental disorders and 0.36 for physical disorders (online Table DS1).

It is important to recognise that the SDS scales are conditionspecific. Respondents were asked to rate the interference to role functioning caused by a particular disorder rather than the interference caused by all their health problems. This focused approach to questioning allows SDS scores to be compared across disorders without adjusting for comorbidity. However, this requires respondents with multiple health problems to sort out the relative effects of their various conditions on their overall functioning. An indication that respondents are able to do this comes from controlled treatment studies that have documented significant improvements in SDS measures of condition-specific role functioning with treatment for generalised anxiety disorder, ${ }^{22}$ panic disorder ${ }^{23}$ and major depression. ${ }^{24}$

Because they are condition-specific, the SDS scales were administered separately for each of the ten mental disorders considered in this report. In the case of the physical disorders, which were only of secondary interest in the WMH surveys, the SDS scales were administered for only one physical disorder per respondent. This one disorder was selected randomly from among all the physical disorders reported by the respondent as being in existence during the 12 months before interview. This method of selection underrepresents comorbid physical disorders, which may be more severe than the pure (non-comorbid) disorders, as a function of the number of such disorders. In order to correct this bias, a weight was applied to each case equal to the number of physical conditions reported by the respondent.

\section{Statistical analysis}

A separate observational record was created for each 12-month physical disorder for which SDS ratings were obtained (i.e. one for each respondent who reported one or more disorders) as well 
as for each 12-month mental disorder reported by each respondent. An otherwise average respondent who met criteria for five 12-month mental disorders and three physical disorders would consequently be represented by six records that had a sum of weights of 8.0: one record for each of the five mental disorders (each with a condition weight of 1.0) and a sixth record for a randomly selected physical disorder (with a condition weight of 3.0).

Standard WMH respondent weights were also applied to each observational record. As noted above, these weights adjusted for differential sampling of respondents in the Part I sample as a function of household size and in the Part II sample as a function of whether or not core disorders were reported in Part I. These weighted records, which are representative of the conditions in the populations, were pooled across samples for comparative analysis. Domain-specific and global SDS means, proportions rated severe or very severe (henceforth referred to as severe) and the standard errors of these estimates were then calculated separately for each condition in each country and in more aggregated form for all high-income and all low- and middle-income countries.

Significance tests were used to test the statistical significance of pair-wide differences in SDS scores across all pairs of conditions. Within-disorder comparisons were also made to determine whether disability ratings differ in low- and middle-income $v$. high-income countries. Between-disorder comparisons were made to determine whether disability ratings are systematically different for physical disorders than mental disorders within countries. All these analyses were then replicated using only the subsample of respondents being treated for physical disorders. Finally, all pairwise comparisons were repeated on a within-person basis: that is, by comparing SDS scores for specific pairs of conditions for the same individual (e.g. a person who had both depression and cancer who provided separate SDS ratings for these conditions). All these significance tests were adjusted for the clustering and weighting of observations. ${ }^{25}$ Significance was consistently evaluated at the 0.05 level with two-sided tests.

\section{Results}

\section{Self-reported disorder prevalence and treatment}

Despite most prevalence estimates of self-reported chronic physical disorders differing significantly between high-income and low- and middle-income countries, the broad pattern of prevalence estimates is quite similar in the two subsamples (Table 1). Chronic back/neck pain, arthritis, chronic headaches and hypertension are estimated to be the four most common disorders in both subsamples. Cancer, diabetes and stomach ulcers are estimated to be among the least common in both subsamples. Five of the ten physical disorders are estimated to be more prevalent in high-income countries and the other five more prevalent in low- and middle-income countries. The percentage of respondents that reported receiving treatment for the disorders that we assessed at the time of interview is generally a good deal higher in high-income than low- and middle-income countries.

The broad rank-ordering of mental disorder prevalence estimates is also fairly similar across subsamples despite the fact that, unlike physical disorders, most mental disorders are estimated to be significantly more prevalent in high-income than in low- and middle-income countries. Specific phobia, depression and social phobia are estimated to be the most prevalent disorders in both subsamples; oppositional defiant disorder and attentiondeficit hyperactivity disorder are estimated to be the least common. As with physical disorders, the percentage of respondents that reported receiving treatment for the disorders that we assessed at the time of interview is consistently higher in high-income than in low- and middle-income countries.

The physical disorders were more likely to be treated than the mental disorders. In high-income countries, $64.9 \%(n=6720)$ of all physical disorders were treated $v .23 .7 \%(n=2637)$ of all mental disorders. In low- and middle-income countries, $53.2 \%$ $(n=2884)$ of physical disorders $v$. only $7.7 \%(n=319)$ of mental disorders were being treated. This pattern also holds for severely disabling disorders, with $77.6 \%(n=2172)$ of severe physical disorders being treated in high-income countries and 64.0\% $(n=763)$ in low- and middle-income countries compared with $35.3 \%$ ( $n=1378)$ of severe mental disorders in high-income countries and $11.9 \%(n=145)$ in low- and middle-income countries. It is noteworthy that these results show the mental-physical treatment gap to be considerably higher in low- and middle-income countries than in high-income countries.

\section{Individual-level disability}

The physical disorders with the highest mean SDS global disability ratings in both subsamples are chronic pain disorders, although between-disorder variation in disability ratings is much greater in high-income than low- and middle-income countries (Table 2). Three physical disorders have significantly higher mean SDS global disability ratings in high-income countries (back/neck pain, headaches, other chronic pain disorders). Three others have significantly higher ratings in low- and middle-income countries (asthma, diabetes, hypertension). A similar pattern of relative disability is found for the proportion of participants rated 'severely' disabled in the total sample as well as among those being treated (online Table DS1).

The mental disorders with the highest mean SDS global disability ratings in both subsamples are bipolar disorder and depression. The lowest ratings are for specific phobia. Four mental disorders (bipolar disorder, depression, generalised anxiety disorder, post-traumatic stress disorder) have significantly higher mean global disability ratings in high-income countries. None has a significantly higher rating in low- and middle-income countries. A similar pattern of relative disability is found for the proportion of participants rated 'severely' disabled in the total sample as well as among those being treated (online Table DS1).

The SDS disability ratings for mental disorders are generally higher than for physical disorders. This is true, using MannWhitney tests, both for mean disability ratings (low- and middle-income $z=3.0, P=0.002$; high-income $z=3.0, \quad P=0.002$ ) and proportions rated severely disabled (low- and middle-income $z=2.5, P=0.011$; high-income $z=2.7, P=0.007)$. Of the 100 logically possible pair-wise disorder-specific mental/physical comparisons, mean ratings are higher for the mental disorder in 91 comparisons in high-income countries and 91 in low- and middle-income countries. Nearly all of these higher mental than physical ratings are statistically significant at the 0.05 level. Comparable results are obtained for severe disability ratings and also for both mean and severe disability ratings when we control for respondent age, gender and education, and when we focus exclusively on the subsamples of participants being treated. (Results available from the author on request.)

Consistently higher mental than physical disability ratings can also be found in both high-income and low- and middle-income countries when individual SDS domains are considered instead of global ratings (Table 3). These differences are much more pronounced for disability in social life and personal relationships than in work or household management. For example, the proportions with severe disability in work functioning associated with mental 


\begin{tabular}{|c|c|c|c|c|c|c|c|c|}
\hline & \multicolumn{4}{|c|}{ Disorder prevalence } & \multicolumn{4}{|c|}{ Treatment prevalence among participants } \\
\hline & \multicolumn{2}{|c|}{ High-income } & \multicolumn{2}{|c|}{ Low- and middle-income } & \multicolumn{2}{|c|}{ High-income } & \multicolumn{2}{|c|}{ Low- and middle-income } \\
\hline & $n^{a}$ & $\%$ (s.e.) & $n^{a}$ & $\%$ (s.e.) & $n^{\mathrm{b}}$ & $\%$ (s.e.) & $n^{\mathrm{b}}$ & $\%$ (s.e.) \\
\hline \multicolumn{9}{|l|}{ Physical disorders } \\
\hline Arthritis & 4434 & $18.1(0.4)^{*}$ & 1627 & $10.0(0.3)$ & 1127 & $50.9(1.8)$ & 229 & $46.6(4.1)$ \\
\hline Asthma & 2524 & $10.0(0.3)^{*}$ & 542 & $3.5(0.2)$ & 494 & $51.0(3.7)$ & 122 & $61.4(5.4)$ \\
\hline Back/neck pain & 5150 & $19.3(0.4)^{*}$ & 3375 & $22.0(0.5)$ & 1632 & $64.8(1.6)^{*}$ & 54 & $43.7(2.3)$ \\
\hline Cancer & 903 & $4.0(0.2)^{*}$ & 112 & $0.6(0.1)$ & 165 & $51.8(5.2)$ & 26 & $59.6(10.2)$ \\
\hline Chronic pain & 1791 & $6.0(0.2)^{*}$ & 1240 & $8.0(0.3)$ & 472 & $71.5(3.2)^{*}$ & 217 & $52.4(4.4)$ \\
\hline Diabetes & 1108 & $4.6(0.2)$ & 564 & $3.9(0.2)$ & 373 & $94.4(1.2)^{*}$ & 168 & $76.6(5.7)$ \\
\hline Headaches & 3363 & $10.9(0.3)^{*}$ & 3260 & $20.8(0.6)$ & 833 & $49.7(1.8)$ & 677 & $49.7(2.2)$ \\
\hline Heart disease & 1168 & $4.7(0.2)^{*}$ & 1063 & $5.9(0.2)$ & 310 & $77.7(2.9)^{*}$ & 171 & 50.9 (5.3) \\
\hline High blood pressure & 3382 & $14.0(0.4)^{*}$ & 2033 & $13.1(0.4)$ & 1194 & $90.2(1.4)^{*}$ & 553 & $69.8(2.7)$ \\
\hline Stomach ulcer & 529 & $1.9(0.1)^{*}$ & 786 & $5.2(0.3)$ & 120 & $67.7(5.4)$ & 173 & $60.6(4.8)$ \\
\hline \multicolumn{9}{|l|}{ Mental disorders } \\
\hline ADHD & 249 & $0.7(0.1)^{\star}$ & 59 & $0.2(0.0)$ & 81 & $29.9(3.7)^{*}$ & 9 & $12.8(4.2)$ \\
\hline Bipolar disorder & 612 & $1.4(0.1)^{*}$ & 174 & $0.7(0.1)$ & 165 & $29.1(2.0)^{*}$ & 23 & $13.4(3.4)$ \\
\hline Depression & 2509 & $5.7(0.2)$ & 1360 & $5.2(0.2)$ & 737 & $29.3(1.1)^{*}$ & 107 & $8.1(1.1)$ \\
\hline GAD & 1064 & $2.4(0.1)^{\star}$ & 360 & $1.4(0.1)$ & 327 & $31.6(1.8)^{*}$ & 22 & $7.2(1.9)$ \\
\hline IED & 391 & $1.1(0.1)$ & 357 & $1.8(0.1)$ & 71 & $16.7(2.2)^{*}$ & 25 & $5.2(1.1)$ \\
\hline ODD & 76 & $0.2(0.0)$ & 34 & $0.2(0.0)$ & 24 & $33.4(7.5)$ & 2 & $13.5(10.8)$ \\
\hline Panic disorder & 685 & $1.6(0.1)^{*}$ & 211 & $0.7(0.1)$ & 212 & $33.1(2.2)^{*}$ & 24 & $9.4(2.4)$ \\
\hline PTSD & 962 & $2.3(0.1)^{\star}$ & 211 & $0.9(0.1)$ & 284 & $29.5(1.9)^{*}$ & 11 & $8.1(3.2)$ \\
\hline Social phobia & 1621 & $4.1(0.1)^{\star}$ & 419 & $1.9(0.1)$ & 342 & $20.8(1.1)^{*}$ & 37 & $9.3(2.0)$ \\
\hline Specific phobia & 2643 & $6.9(0.2)^{*}$ & 829 & $3.4(0.2)$ & 394 & $13.2(0.8)^{*}$ & 59 & $5.5(0.9)$ \\
\hline
\end{tabular}

disorders in low- and middle-income and high-income countries (19.4-21.7\%, $n=673-2135)$ are only slightly higher than the proportions associated with physical disorders $(17.9-18.1 \%, n=874-$ 2028). The proportions with severe disability in social functioning associated with mental disorders $(21.8-28.0 \%, n=775-2758)$, in comparison, are dramatically higher than those associated with physical disorders $(10.3-8.9 \%, n=513-1168)$. Similar patterns of mental/physical differences are found when we compare mean disability ratings rather than the proportions rated as severe and when we compare both means and proportions rated as severe among people being treated (see online Table DS1). In addition, an attenuated version of the same general pattern holds when we compare people being treated for physical disorders to all (i.e. being treated or not) mental disorders to address the concern that the more superficial assessment of physical than mental disorders might have resulted in the inclusion of a sub-threshold of individuals with physical disorders who might have low disability (online Table DS1).

\section{Discussion}

Four key findings emerged from the analyses. First, respondents generally attributed more disability to their mental rather than physical disorder. Second, the higher disability of mental compared with physical disorders held as strongly in low- and middle-income countries as in high-income countries. Third, the higher aggregate disability of mental than physical disorder was much more pronounced for disability in social and personal relationships than in productive (work and housework) roles. Fourth, the proportion of participants receiving treatment at the time of interview was much lower for mental than physical disorders in high-income countries and even more so in low- and middle-income countries both in the total sample and when we focused exclusively on participants rated as having a severely disabling disorder. These findings substantially extend the results of previous studies, none of which documented comparability in the disabilities associated with such a varied set of physical and mental disorders, or disaggregated disability into the domains considered here to detect the greater relative impact of mental $v$. physical disorders in social/personal domains compared with productive role domains. ${ }^{2,4-7}$

These results are limited by a number of sampling and measurement problems. With regard to sampling, results could be influenced by a truncation of the severity spectrum of physical disorders. For example, persons facing the end stage of a chronic physical disease might be institutionalised or not willing or able to participate in an interview to a greater extent than people with severe mental disorders, leading to under-estimation of the relative disability of physical compared with mental disorders. Whether such a difference in sample bias actually exists, though, is unknown.

\section{Limitations}

There were a number of measurement problems in the analysis. One is that the physical conditions checklist did not include the infectious diseases that play such an important part in morbidity in low- and middle-income countries. Our results consequently can be generalised only to chronic cardiovascular, digestive, metabolic, musculoskeletal, pain and respiratory conditions. However, the conditions considered are important sources of morbidity even in low- and middle-income countries and the results are consequently relevant to those countries despite the exclusion of infectious diseases.

Another measurement problem is that the physical disorders were assessed by a simple self-report rather than by abstracting medical records or administering medical examinations. Mental disorders were assessed more comprehensively with a fully 


\begin{tabular}{|c|c|c|c|c|c|c|c|c|}
\hline & \multicolumn{4}{|c|}{ Mean disability ratings } & \multicolumn{4}{|c|}{ Proportion rated as severely disabled } \\
\hline & \multicolumn{2}{|c|}{ High-income } & \multicolumn{2}{|c|}{ Low- and middle-income } & \multicolumn{2}{|c|}{ High-income } & \multicolumn{2}{|c|}{ Low- and middle-income } \\
\hline & $n^{\mathrm{a}}$ & Mean (s.e.) & $n^{\mathrm{a}}$ & Mean (s.e.) & $n^{\mathrm{b}}$ & $\%$ (s.e.) & $n^{\mathrm{b}}$ & $\%$ (s.e.) \\
\hline \multicolumn{9}{|l|}{ Physical disorders } \\
\hline Arthritis & 2140 & $3.5(0.1)$ & 580 & $3.8(0.2)$ & 526 & $23.3(1.5)$ & 127 & $22.8(3.0)$ \\
\hline Asthma & 1040 & $1.9(0.2)^{*}$ & 228 & $3.7(0.4)$ & 119 & $8.2(1.4)^{*}$ & 44 & $26.9(5.4)$ \\
\hline Back/neck pain & 2602 & $4.8(0.1)^{*}$ & 1379 & $3.9(0.1)$ & 912 & $34.6(1.5)^{*}$ & 305 & $22.7(1.8)$ \\
\hline Cancer & 285 & $2.0(0.3)$ & 42 & $3.5(0.7)$ & 60 & $16.6(3.2)$ & 8 & 23.9 (10.3) \\
\hline Chronic pain & 685 & $5.2(0.2)^{*}$ & 418 & $3.8(0.3)$ & 296 & $40.9(3.6)^{*}$ & 109 & $24.8(3.8)$ \\
\hline Diabetes & 408 & $2.1(0.4)^{*}$ & 215 & $3.5(0.5)$ & 49 & $13.6(3.4)$ & 39 & $23.7(6.1)$ \\
\hline Headaches & 1709 & $5.4(0.1)^{\star}$ & 1440 & $4.3(0.2)$ & 751 & $42.1(1.9)^{\star}$ & 401 & $28.1(2.1)$ \\
\hline Heart disease & 396 & $3.3(0.3)$ & 319 & $3.8(0.4)$ & 83 & $26.5(3.9)$ & 63 & $27.8(5.2)$ \\
\hline High blood pressure & 1365 & $1.2(0.1)^{\star}$ & 797 & $3.5(0.2)$ & 91 & $5.3(0.9)^{*}$ & 144 & $23.8(2.6)$ \\
\hline Stomach ulcer & 170 & $2.9(0.4)$ & 312 & $3.3(0.4)$ & 31 & $15.3(3.9)$ & 59 & $18.3(3.6)$ \\
\hline \multicolumn{9}{|l|}{ Mental disorders } \\
\hline $\mathrm{ADHD}$ & 228 & $5.4(0.2)$ & 45 & $5.1(0.5)$ & 87 & $37.6(3.6)$ & 14 & $24.3(7.4)$ \\
\hline Bipolar disorder & 588 & $7.4(0.1)^{*}$ & 158 & $6.4(0.3)$ & 419 & $68.3(2.6)^{*}$ & 87 & $52.1(4.9)$ \\
\hline Depression & 1536 & $7.1(0.1)^{\star}$ & 1241 & $6.3(0.1)$ & 1028 & $65.8(1.6)^{*}$ & 622 & $52.0(1.8)$ \\
\hline GAD & 1002 & $6.6(0.1)^{\star}$ & 328 & $5.5(0.3)$ & 576 & $56.3(1.9)^{*}$ & 127 & $42.0(4.2)$ \\
\hline IED & 387 & $4.9(0.2)$ & 345 & $4.4(0.3)$ & 136 & $36.3(2.8)$ & 106 & $27.8(3.6)$ \\
\hline ODD & 67 & $5.3(0.5)$ & 32 & $5.4(0.6)$ & 29 & $34.2(6.0)$ & 12 & 41.3 (10.3) \\
\hline Panic disorder & 641 & $5.8(0.2)$ & 189 & $5.2(0.4)$ & 317 & $48.4(2.6)^{\star}$ & 67 & $38.8(4.7)$ \\
\hline PTSD & 571 & $6.5(0.2)^{*}$ & 112 & $5.6(0.4)$ & 329 & $54.8(2.8)^{*}$ & 53 & 41.2 (7.3) \\
\hline Social phobia & 1621 & $5.0(0.1)$ & 419 & $5.4(0.2)$ & 593 & $35.1(1.4)$ & 164 & $41.4(3.6)$ \\
\hline Specific phobia & 2643 & $3.4(0.1)$ & 829 & $3.3(0.1)$ & 537 & $18.6(1.1)$ & 144 & $16.2(1.6)$ \\
\hline $\begin{array}{l}\text { ADHD, attention-deficit hype } \\
\text { stress disorder. } \\
\text { a. Number of respondents } \\
\text { substantially lower than thos } \\
\text { scores were obtained only } f \\
\text { because participants with } m \\
\text { with missing Sheehan score } \\
\text { b. Number of participants ra } \\
* P<0.05 \mathrm{v} \text {. low- and middle }\end{array}$ & $\begin{array}{l}\text { heehan s } \\
1 \text { becaus } \\
\text { sample of } \\
\text { es on She } \\
\text { her than } \\
\text { ing a sev } \\
\text { 2-test. }\end{array}$ & $\begin{array}{l}\text { eneralised anxiet } \\
\text { for the randomly } \\
\text { prevalence estir } \\
\text { omly selected ph } \\
\text { scores were om } \\
\text { normally be ex } \\
\text { disabling disorde }\end{array}$ & $\begin{array}{l}\text { lected phy } \\
\text { es in Table } \\
\text { cal disorde } \\
\text { ted from this }\end{array}$ & $\begin{array}{l}\text { sorder or the m } \\
\text { based on all re } \\
\text { numbers for me } \\
\text { but not Table } 1 . \\
\text { spondent refus }\end{array}$ & $\begin{array}{l}\text { tisorder. } \\
\text { dents wh } \\
\text { tisorders } \\
\text { arrors in } \\
\text { intervie }\end{array}$ & $\begin{array}{l}\text { tional defiant d } \\
\text { t the numbers } \\
\text { ed the disorder } \\
\text { able are slightly } \\
\text { ern European } \\
\text { ording errors. }\end{array}$ & $\begin{array}{l}\text { physical di } \\
\text { nereas the } \\
\text { wer than th } \\
\text { veys led to }\end{array}$ & $\begin{array}{l}\text { aumatic } \\
\text { are } \\
\text { Fable } 1 \\
\text { nber of cases }\end{array}$ \\
\hline
\end{tabular}

structured lay-administered diagnostic interview. The more superficial assessment of physical disorders might have led to the inclusion of more individuals with sub-threshold physical disorders than those with sub-threshold mental disorders, introducing an artificial lowering of the estimated disability of physical disorders, although we addressed this in our analysis of treated physical conditions. It might also have led to artificial overlap between the assessments of mental and physical disorders to the extent that core symptoms of some physical conditions (e.g. headache, unexplained chronic pain) are markers of underlying mental disorders, although this would have attenuated physical/mental differences by increasing overlap between the two classes of disorders. In addition, the use of a self-report checklist almost certainly led to an underestimation of undiagnosed silent physical conditions. As the latter are likely to be less disabling than symptom-based conditions or diagnosed silent conditions, this bias presumably led to an artificial increase in the estimated disability of physical disorders.

Some of the WMH physical disorder prevalence estimates are lower than those in gold-standard assessments. For example, the population prevalence of diabetes has been assessed in a number of community surveys using glucose tolerance tests on blood samples. ${ }^{26} \mathrm{~A}$ meta-analysis of these studies suggests that the prevalence of diabetes is highest in North America (9.2\%) and Europe $(8.4 \%)$, lower in India and most of Latin America $(5-8 \%)$, and lowest in most of Africa and China $(2-5 \%) .{ }^{27}$ The $\mathrm{WMH}$ prevalence estimates, $4.6 \%$ in high-income countries and $3.9 \%$ in low- and middle-income countries, are lower than these gold-standard estimates, presumably reflecting the fact that the latter include undiagnosed cases.
In other instances the WMH prevalence estimates are higher than those in gold-standard assessments. For example, cancer prevalence data have been assembled from various administrative databases and registries in a number of countries. ${ }^{28}$ Meta-analysis of these data suggest that cancer is more common in high-income than low- and middle-income countries, with the highest prevalence in North American (1.5\% of the population aged 15 and older diagnosed within the past 5 years), followed by Western Europe (1.2\%), Australia and New Zealand (1.1\%), Japan (1.0\%), Eastern Europe (0.7\%), Latin America and the Caribbean $(0.4 \%)$, with a much lower estimated prevalence in the rest of the world $(0.2 \%)$. The much higher cancer prevalence estimates in the WMH data, $4.0 \%$ in high-income countries and $0.6 \%$ in low- and middle-income countries, presumably reflect the fact that cancer survivors who were diagnosed and treated more than 5 years ago, although not counted in cancer prevalence estimates because they have the same survival rates as the general population, often consider themselves still to have cancer and report this in community surveys.

Based on comparisons such as these with gold-standard assessments, caution is needed in interpreting the $\mathrm{WMH}$ prevalence estimates of physical disorders. However, the fact that the same general pattern of higher disability among mental disorders compared with physical disorders held in comparisons of individuals treated for physical disorders argues strongly that the finding of higher SDS disability associated with mental than with physical disorders is not due to imprecision in the measurement of physical disorders.

Another measurement problem involves the fact that disability was assessed with brief self-report scales rather than clinical evaluations. This might have introduced upward bias in the reported 
Table 3 Sheehan Disability Scale global and domain-specific ratings (proportion rated severely disabled) aggregated across physical (total and treated) and mental (total) disorders in high-income and low- and middle-income World Mental Health countries

\begin{tabular}{|c|c|c|c|c|c|c|}
\hline & \multicolumn{2}{|c|}{ Physical disorders } & \multicolumn{2}{|c|}{ Treated physical disorders } & \multicolumn{2}{|c|}{ Mental disorders } \\
\hline & $n^{\mathrm{a}}$ & \% (s.e.) & $n^{\mathrm{a}}$ & \% (s.e.) & $n^{\mathrm{a}}$ & \% (s.e.) \\
\hline \multicolumn{7}{|l|}{ Global } \\
\hline High-income & 2918 & $23.8(0.7)^{\dagger}$ & 2172 & $28.6(1.0)^{\dagger}$ & 4051 & $41.3(0.8)^{*}$ \\
\hline Low- and middle-income & 1299 & $245(1.2)^{\dagger}$ & 735 & $29.4(1.6)^{\dagger}$ & 1396 & 37.6 (1.3) \\
\hline \multicolumn{7}{|l|}{ Work } \\
\hline High-income & 2028 & $18.1(0.7)$ & 1546 & $22.4(1.0)^{\dagger}$ & 2135 & $21.7(0.7)^{\star}$ \\
\hline Low- and middle-income & 874 & $17.9(1.0)$ & 517 & $21.7(1.4)$ & 673 & $19.4(0.9)$ \\
\hline \multicolumn{7}{|l|}{ Home } \\
\hline High-income & 2146 & $17.8(0.6)$ & 1608 & $21.3(0.9)^{\star \dagger}$ & 2011 & $19.9(0.7)$ \\
\hline Low- and middle-income & 881 & $16.7(1.0)^{\dagger}$ & 517 & $19.8(1.4)$ & 795 & $20.5(1.0)^{\dagger}$ \\
\hline \multicolumn{7}{|l|}{ Social } \\
\hline High-income & 1168 & $0.9(0.4)^{\dagger}$ & 887 & $10.7(0.6)^{\dagger}$ & 2758 & $28.0(0.8)^{*}$ \\
\hline Low- and middle-income & 513 & $10.3(0.7)^{\dagger}$ & 324 & $13.7(1.1)^{\dagger}$ & 775 & $21.8(1.0)$ \\
\hline \multicolumn{7}{|l|}{ Close relationships } \\
\hline High-income & 850 & $6.5(0.4)^{\dagger}$ & 630 & $7.8(0.6)^{\dagger}$ & 2375 & $24.3(0.7)^{*}$ \\
\hline Low- and middle-income & 495 & $9.0(0.7)^{\dagger}$ & 305 & $11.7(1.0)^{\dagger}$ & 785 & $21.3(1.1)$ \\
\hline
\end{tabular}

disability caused by mental disorders compared with physical disorders to the extent that people with mental disorders gave overly pessimistic appraisals of their functioning. This would seem to be an unlikely interpretation, though, in that the associations of SDS ratings with reported numbers of days out of role - a more objective indicator of disability than the SDS ratings - were found to be equivalent for mental and physical disorders. Furthermore, within-person comparison, which controlled for individual differences in perceptions, found similar results.

Another possibility is that the SDS questions might have been biased in the direction of assessing the disabilities associated with mental more than physical disorders. This would seem unlikely, though, as the SDS questions are quite broad and cover all the main areas of adult role functioning. Another possible limitation is that the SDS focused on the 'worst month' in the past year, introducing recall error that possibly was more extreme for physical disorders than mental disorders. In addition, between-disorder differences in persistence were not taken into consideration, which means that particular disorders might have been more dominant in severity ratings than suggested here if they were more persistently severe than others. The aggregate disability estimates should be interpreted cautiously because of these limitations regarding the recall period.

A final measurement problem concerning the assessment of disability relates to our use of a condition-specific measurement approach. This is an attractive approach from a statistical perspective, compared with an unconditional measurement approach (i.e. an approach that simply assesses overall disability without asking the respondent to make inferences about the conditions that caused the disability), because it produces condition-specific estimates directly, avoiding the need to rely on multivariate equations that adjust for the effects of comorbidity in predicting overall disability. However, this advantage in analytic simplicity is achieved by requiring respondents with comorbid conditions to perform the difficult task of making judgements about the effects of individual conditions on their functioning. Because of likely imprecision in these assessments, it would be useful to replicate the results reported here in multivariate analyses that evaluate the separate and joint effects of comorbid conditions in predicting an unconditional measure of disability. Unfortunately, the statistical methods needed to estimate models of this sort are very complex, ${ }^{29}$ making it difficult to carry out such analyses.

\section{Burden of illness and likelihood of treatment}

Within the context of these limitations, the results reported here are consistent with previous comparative burden-of-illness studies in suggesting that musculoskeletal disorders and major depression are the disorders with the largest contribution to disability at the individual level both in high-income and in low- and middleincome countries. Previous studies have documented this pattern only for the USA, ${ }^{30-32}$ although the importance of depression has also been documented throughout the world in the World Health Surveys. ${ }^{7}$ The current report replicates the World Health Surveys results regarding depression and documents for the first time the cross-national importance of musculoskeletal disorders. As noted above, the WMH results also suggest that mental disorders are especially disabling to personal relationships and social life, which implies that they are disabling more because they create psychological barriers rather than physical barriers to functioning. Among these barriers are limitations in cognitive and motivational capacities, affect regulation, embarrassment and stigma, ${ }^{33}$ and a tendency to amplify physical symptoms ${ }^{34}$ and associated disability. ${ }^{35}$

Given this greater disability of mental than physical disorders, it is disturbing to find that only a minority of people with severe mental disorders receive treatment and that treatment is substantially more common for comparably severe physical disorders. In high-income countries, seriously disabling mental disorders are only about half as likely to be treated as seriously disabling physical disorders ( $35.3 \%$ v. $77.6 \%)$, and only about $20 \%$ as likely to be treated compared with severe physical disorders in low- and middle-income countries (11.9\% v. 64.0\%). This low treatment rate is consistent with the low rate of recognition and treatment of mental disorders in primary care, especially if comorbid with physical disorders. ${ }^{36,37}$ Combined with the burden of disability that mental disorders produce, the low treatment rates call for more attention to mental disorders.

Implications of the WMH findings for treatment are not clear because, even though treatment effectiveness trials document that common anxiety and mood disorders can often be successfully treated, ${ }^{38,39}$ uncertainties exist regarding long-term outcomes. Another limitation of existing trials is that they focused on symptoms and did little to assess the effects of treatment on reducing disability. ${ }^{38,39}$ In particular, long-term functional outcomes are important to track because residual disability and 
recurrence of disability are major problems with chronic mental disorders. ${ }^{40}$ Despite this uncertainty about long-term outcomes, the results reported here argue strongly that, on the basis of population disease burden associated with disorder-specific disability, more attention should be given to the treatment of mental disorders and that this is especially so in low- and middle-income countries.

Johan Ormel, PhD, Department of Psychiatry \& Department of Epidemiology and Bioinformatics, University Medical Center Groningen, and Graduate School of Behavioural and Cognitive Neurosciences \& Graduate School for Experimental Psychopathology, University of Groningen, The Netherlands; Maria Petukhova, PhD, Department of Health Care Policy, Harvard Medical School, Boston, Massachusetts, USA; Somnath Chatterji, MD, Measurement and Health Information Systems Unit, World Health Organization, Geneva, Switzerland; Sergio Aguilar-Gaxiola, MD, PhD, Center for Reducing Health Disparities, University of California Davis, California, USA; Jordi Alonso, MD, PhD, Health Services Research Unit, Institut Municipal d'Investigacio Medica, Barcelona, Spain; Matthias C. Angermeyer, MD, University of Leipzig, Department of Psychiatry, Germany; Evelyn J. Bromet, PhD, SUNY Stony Brook, New York, USA; Huibert Burger, MD, PhD, Department of Psychiatry \& Department of Epidemiology and Bioinformatics, University Medical Center Groningen, and Graduate School of Behavioural and Cognitive Neurosciences \& Graduate School for Experimental Psychopathology, University of Groningen, The Netherlands; Koen Demyttenaere, MD, PhD, University Hospital, Gasthuisberg, Leuven, Belgium; Giovanni de Girolamo, MD, Department of Mental Health, AUSL d Bologna, Italy; Josep Maria Haro, MD, MPH, PhD, Sant Joan de Deu-SSM, Barcelona, Spain; Irving Hwang, MPH, Department of Health Care Policy, Harvard Medical School, Boston, Massachusetts, USA; Elie Karam, MD, Department of Psychiatry and Psychology, St George Hospital University Medical Center, and Institute for Development, Research, Advocacy and Applied Care (IDRAAC), Lebanon; Norito Kawakami, MD, Department of Mental Health, University of Tokyo Graduate School of Medicine, Tokyo, Japan; Jean Pierre Lépine, MD, Hospital Fernand Widal, Paris, France; María Elena Medina-Mora, PhD, Division of Epidemiological and Social Research, Mexican Institute of Psychiatry, Mexico City, Mexico; José Posada-Villa MD, Colegio Mayor de Cundinamarca University, Saldarriaga Concha Foundation, Colombia; Nancy Sampson, BA, Department of Health Care Policy, Harvard Medica School, Boston, Massachusetts, USA; Kate Scott, PhD, Wellington School of Medicine and Health Sciences, Otago University, New Zealand; $T$. Bedirhan Üstün, MD, Classifications and Terminology Unit, World Health Organization, Geneva, Switzerland Michael Von Korff, SCD, Center for Health Studies, Group Health Cooperative, Seattle, USA; David R.Williams, PhD, MPH, Institute for Social Research, University of Michigan, Ann Arbor, Michigan, USA; Mingyuan Zhang, MD, Shanghai Mental Health Center, Shanghai, China; Ronald C. Kessler, PhD, Department of Health Care Policy, Harvard Medical School, Boston, Massachusetts, USA

Correspondence: Ronald C. Kessler, Department of Health Care Policy, Harvard Medical School, 180 Longwood Avenue, Boston, Massachusetts, 02115 USA.Email: kessler@ hcp.med.harvard.edu

\section{Acknowledgements}

The surveys included in this report were carried out in conjunction with the World Healt Organization (WHO) World Mental Health (WMH) Survey Initiative. We thank the WMH staff for assistance with instrumentation, fieldwork and data analysis. These activities were supported by the US National Institute of Mental Health (NIMH; R01-MH070884), the John D. and Catherine T. MacArthur Foundation, the Pfizer Foundation, the US Public Health Service (R13-MH066849, R01-MH069864 and R01 DA016558), the Fogarty International Center (FIRCA R01-TW006481), the Pan American Health Organization (PAHO), Eli Lilly, Ortho-McNeil Pharmaceutical, Inc., GlaxoSmithKline, and Bristol-Myers Squibb. A complete list of WMH publications can be found at www.hcp.med.harvard.edu/wmh/. The Mexican National Comorbidity Survey is supported by The National Institute of Psychiatry Ramon de la Fuente (INPRFMDIES 4280) and by the National Council on Science and Technology (CONACyT-G30544-H), with supplemental support from PAHO. The Lebanese survey is supported by the Lebanese Ministry of Public Health, the WHO (Lebanon) and unrestricted grants from Janssen Cilag, Eli Lilly, GlaxoSmithKline, Roche, Novartis, Fogerty (R03TW0006481) and anonymous donations. The European Study of the Epidemiology of Mental Disorders project was funded by the European Commission (Contracts QLG5-1999-01042 SANCO 2004123), the Piedmont Region (Italy), Fondo de Investigación Sanitaria, Instituto de Salud Carlos III, Spain (FIS 00/0028), Ministerio de Ciencia y Tecnología, Spain (SA 2000-158-CE), Departament de Salut, Generalitat de Catalunya, Spain, other local agencies and by an unrestricted educational grant from GlaxoSmithKline. The Chinese World Mental Health Survey Initiative is supported by the Pfizer Foundation. The Colombian Nationa Study of Mental Health is supported by the Ministry of Social Protection, with supplemental support from the Saldarriaga Concha Foundation. The World Mental Health Japan Survey is supported by the Grant for Research on Psychiatric and Neurological Diseases and Mental Health (H13-SHOGAI-023, H14-TOKUBETSU-026, H16-KOKORO-013) from the Japan Ministry of Health, Labour and Welfare. The New Zealand Mental Health Survey is supported by the New Zealand Ministry of Health, Alcohol Advisory Council, and the Health Research Council. The South Africa Stress and Health Study is supported by the NIMH (R01-MH059575) and National Institute of Drug Abuse (NIDA) with supplemental funding from the South African Department of Health and the University of Michigan (NIMH: HHSN271200700030C). The Ukraine Comorbid Mental Disorders during Periods of Social Disruption study is funded by the NIMH (R01-MH61905). The US National Comorbidity Survey Replication is supported by the NIMH (U01-MH60220 with supplemental support from NIDA, the substance Abuse and Mental Health Services Administration, the Robert Wood Johnson Foundation (Grant 044780), and the John W. Alden Trust.

\section{References}

1 World Health Organization. World Health Statistics 2006. WHO, 2006

2 Katschnig H, Freeman H, Sartorius N. Quality of Life in Mental Disorders. John Wiley \& Sons, 1997

3 Murray CJL, Lopez AD. The Global Burden of Disease: A Comprehensive Assessment of Mortality and Disability from Diseases, Injuries and Risk Factors in 1990 and Projected to 2020. Harvard University Press, 1996.

4 Berto P, D'llario D, Ruffo P, Di Virgilio R, Rizzo F. Depression: cost-of-illness studies in the international literature, a review. J Ment Health Policy Econ 2000; 3: 3-10.

5 Maetzel A, Li L. The economic burden of low back pain: a review of studies published between 1996 and 2001. Best Pract Res Clin Rheumatol 2002; 16: 23-30.

6 Reed SD, Lee TA, Mccrory DC. The economic burden of allergic rhinitis: a critical evaluation of the literature. Pharmacoeconomics 2004; 22: 345-61.

7 Moussavi S, Chatterji S, Verdes E, Tandon A, Patel V, Üstün B. Depression, chronic diseases, and decrements in health: results from the World Health Surveys. Lancet 2007; 370: 851-8.

8 Kessler RC, Üstün TB. The World Mental Health (WMH) Survey Initiative Version of the World Health Organization (WHO) Composite International Diagnostic Interview (CIDI). Int J Methods Psychiatr Res 2004; 13: 93-121.

9 Centers for Disease Control and Prevention. Health, United States 2004. Centers for Disease Control, 2004.

10 Knight M, Stewart-Brown S, Fletcher L. Estimating health needs: the impact of a checklist of conditions and quality of life measurement on health information derived from community surveys. J Public Health Med 2001; 23: 179-86.

11 Baker M, Stabile M, Deri C. What do self-reported, objective, measures of health measure? J Hum Resour 2001; 39: 1067-93.

12 Bergmann MM, Byers T, Freedman DS, Mokdad A. Validity of self-reported diagnoses leading to hospitalization: a comparison of self-reports with hospital records in a prospective study of American adults. Am J Epidemiol 1998; 147: 969-77.

13 Edwards WS, Winn DM, Kurlantzick V, Sheridan S, Berk ML, Retchin S, Collins JG. Evaluation of National Health Interview Survey diagnostic reporting. Vital Health Stat 2 1994; 120: 1-116.

14 Kriegsman DM, Penninx BW, van Eijk JT, Boeke AJ, Deeg DJ. Self-reports and general practitioner information on the presence of chronic diseases in community dwelling elderly. A study on the accuracy of patients' self-reports and on determinants of inaccuracy. J Clin Epidemiol 1996; 49: 1407-17.

15 American Psychiatric Association. Diagnostic and Statistical Manual of Mental Disorders (4th edn) (DSM-IV). APA, 1994.

16 Haro JM, Arbabzadeh-Bouchez S, Brugha TS, di Girolamo G, Guyer ME, Jin R, Lépine JP, Mazzi F, Reneses B, Vilagut Saiz G, Sampson NA, Kessler RC. Concordance of the Composite International Diagnostic Interview Version 3.0 (CIDI 3.0) with standardized clinical assessments in the WHO World Mental Health Surveys. Int J Methods Psychiatr Res 2006; 15: 167-80.

17 Reijneveld SA, Stronks K. The validity of self-reported use of health care across socioeconomic strata: a comparison of survey and registration data. Int J Epidemiol 2001; 30: 1407-14.

18 Hambrick JP, Turk CL, Heimberg RG, Schneier FR, Liebowitz MR. Psychometric properties of disability measures among patients with social anxiety disorder. J Anxiety Disord 2004; 18: 825-39.

19 Leon AC, Olfson M, Portera L, Farber L, Sheehan DV. Assessing psychiatric impairment in primary care with the Sheehan Disability Scale. Int J Psychiatry Med 1997; 27: 93-105.

20 Connor KM, Davidson JR. SPRINT: a brief global assessment of post-traumatic stress disorder. Int Clin Psychopharmacol 2001; 16: 279-84.

21 Pallanti S, Bernardi S, Quercioli L. The Shorter PROMIS Questionnaire and the Internet Addiction Scale in the assessment of multiple addictions in a highschool population: prevalence and related disability. CNS Spectr 2006; 11: 966-74.

22 Davidson J, Yaryura-Tobias J, DuPont R, Stallings L, Barbato LM, van der Hoop RG, Li D. Fluvoxamine-controlled release formulation for the treatment of generalized social anxiety disorder. J Clin Psychopharmacol 2004; 24: $118-25$

23 Bertani A, Perna G, Migliarese G, Di Pasquale D, Cucchi M, Caldirola D, Bellodi L. Comparison of the treatment with paroxetine and reboxetine in panic disorder: a randomized, single-blind study. Pharmacopsychiatry 2004; 37: $206-10$ 
24 Hudson JI, Perahia DG, Gilaberte I, Wang F, Watkin JG, Detke MJ. Duloxetine in the treatment of major depressive disorder: an open-label study. BMC Psychiatry 2007; 7: 43

25 Kish L, Frankel MR. Inferences from complex samples. J R Stat Soc 1974; 36 $1-37$.

26 Roglic G, Unwin N, Bennett PH, Mathers C, Tuomilehto J, Nag S, Connolly V King $\mathrm{H}$. The burden of mortality attributable to diabetes: realistic estimates for the year 2000. Diabetes Care 2005; 28: 2130-5.

27 International Diabetes Federation. Diabetes Atlas (3rd edn). International Diabetes Federation, 2005

28 Pisani P, Bray F, Parkin DM. Estimates of the world-wide prevalence of cancer for 25 sites in the adult population. Int J Cancer 2002; 97: 72-81.

29 Merikangas KR, Ames M, Cui L, Stang PE, Üstün TB, Von Korff M, Kessler RC. The impact of comorbidity of mental and physical conditions on role disability in the US adult household population. Arch Gen Psychiatry 2007; 64: $1180-8$

30 Druss BG, Rosenheck RA, Sledge WH. Health and disability costs of depressive illness in a major U.S. corporation. Am J Psychiatry 2000; 157: $1274-8$.

31 Manuel DG, Schultz SE, Kopec JA. Measuring the health burden of chronic disease and injury using health adjusted life expectancy and the Health Utilities Index. J Epidemiol Community Health 2002; 56: 843-50.

32 Wang PS, Beck A, Berglund P, Leutzinger JA, Pronk N, Richling D, Schenk TW Simon G, Stang P, Üstün TB, Kessler RC. Chronic medical conditions and work performance in the health and work performance questionnaire calibration surveys. J Occup Environ Med 2003; 45: 1303-11.
33 Buist-Bouwman MA, de Graaf R, Vollebergh WA, Ormel J. Comorbidity of physical and mental disorders and the effect on work-loss days. Acta Psychiatr Scand 2005; 111: 436-43.

34 Barsky AJ, Goodson JD, Lane RS, Cleary PD. The amplification of somatic symptoms. Psychosom Med 1988; 50: 510-9.

35 Kessler RC, Ormel J, Demler O, Stang PE. Comorbid mental disorders account for the role impairment of commonly occurring chronic physical disorders: results from the National Comorbidity Survey. J Occup Environ Med 2003; 45: 1257-66.

36 Thompson C, Kinmonth AL, Stevens L, Peveler RC, Stevens A, Ostler KJ, Pickering RM, Baker NG, Henson A, Preece J, Cooper D, Campbell MJ. Effects of a clinical-practice guideline and practice-based education on detection and outcome of depression in primary care: Hampshire Depression Project randomised controlled trial. Lancet 2000; 355: 185-91.

37 Tiemens BG, Ormel J, Jenner JA, van der Meer K, Van Os TW, van den Brink $\mathrm{RH}$, Smit A, van den Brink W. Training primary-care physicians to recognize, diagnose and manage depression: does it improve patient outcomes? Psychol Med 1999; 29: 833-45.

38 Hyman S, Chisholm D, Kessler RC, Patel V, Whiteford H. Mental Disorders. In Disease Control Priorities in Developing Countries (eds DT Jamison, JG Breman, AR Measham, G Alleyne, M Claeson, DB Evans, P Jha, A Mills, P Musgrove): 605-25. Oxford University Press, 2006.

39 Nathan PE, Gorman JM. A Guide to Treatment That Works. Oxford University Press, 1998.

40 Ormel J, Oldehinkel AJ, Nolen WA, Vollebergh W. Psychosocial disability before, during, and after a major depressive episode: a 3-wave populationbased study of state, scar, and trait effects. Arch Gen Psychiatry 2004; 61: 387-92. 